\title{
Reduction of flatfish habitat as a consequence of the proliferation of an invasive mollusc
}

\author{
C. Kostecki ${ }^{a, *}$, S. Rochette ${ }^{a}$, R. Girardin ${ }^{a}$, M. Blanchard ${ }^{b}$, N. Desroy ${ }^{c}$ and O. Le Pape ${ }^{a}$
}

\author{
a Université Européenne de Bretagne, UMR 985 Agrocampus Ouest, Inra Ecologie \& Santé des \\ Ecosystèmes, Ecologie halieutique, Agrocampus Ouest, 65 rue de St Brieuc, CS 84215, 35042 \\ Rennes, France \\ ${ }^{\mathrm{b}}$ IFREMER, Laboratoire Benthos, département DYNECO, BP70, 29280 Plouzané, France \\ ${ }^{c}$ IFREMER, Laboratoire Environnement-Ressources Finistère-Bretagne Nord, CRESCO, 38 rue du \\ Port Blanc, BP 80108, 35801 Dinard Cedex, France
}

\author{
* Corresponding author: Caroline Kostecki, Tel.: + 33 (0) 223485456 ; fax: + 33 (0) 223485535 \\ email address : caroline.kostecki@agrocampus-ouest.fr ; caroline.kostecki@yahoo.fr
}

\begin{abstract}
:
Coastal bays provide habitats for juveniles and adults of many marine species. Mont Saint-Michel Bay (MSMB, France) hosts a highly diversified ichtyological community and constitutes one of the most important nursery grounds for many commercially exploited marine species, such as sea bass, flatfish, clupeids and rays in the English Channel. Besides, MSMB also suffers from the massive invasion of an exotic mollusc, the American slipper-limpet (Crepidula fornicata, L.). This species arrived four decades ago and now represents the main filters biomass in the bay $(150 \mathrm{Mt})$, an order of magnitude larger than local farmed and natural shellfishes. Recent analyses underlined the impact of this small gastropod on the trophic structure of this bay and its negative influence on juvenile sole densities in the nursery grounds. In the present study, the effect of the extension of the slipper-limpet on flatfish (common sole Solea solea, L.; plaice Pleuronectes platessa, L.; brill Scophthalmus rhombus, L. and flounder Platichthys flesus, L.) spatial distribution has been explored from a geostatistical approach. Data collected during surveys realised in the MSMB at the end of the seventies and three decades later have been used to build interpolated maps of i) slipper-limpet and ii) flatfish spatial distributions. Thirty years ago, slipper-limpets were concentrated in a small area, in the western part of the MSMB, while today they are occupying half of the bay. This fast proliferation led to the decrease of available surface for flatfishes, which previously spread on the whole bay and are now restricted to its eastern part. The present study highlighted the negative influence of slipper-limpet extension in MSMB on fish habitat. The negative effect induced by slipper-limpet invasion seems to be more related to changes in the substrate than to trophic interactions. This invasion has possible consequences on flatfish population renewal at large scale and may also damage other benthic or demersal species, like rays.
\end{abstract}

Keywords : Spatial competition; flatfish habitat; Crepidula fornicata; invasive species; Mont SaintMichel Bay 


\section{Introduction}

Coastal and estuarine systems are the most productive environments in the world and represent half of the oceanic production (Costanza et al., 1997). They are essential fish habitats for many marine species since they provide nursery grounds for their juveniles (van der Veer, 2000; Beck et al., 2001) and also because they constitute feeding grounds for adults (Peterson, 2003). The available coastal and estuarine habitats and their quality have a considerable influence on the renewal of marine population (Rijnsdorp et al., 1992; Gibson, 1994). Because of the very high human pressure in these areas, juveniles, but also significant amount of adults, confined within these coastal and estuarine habitats can be affected by habitat degradation and related populations can be reduced (Johnson et al., 1998; Peterson et al., 2000; Le Pape et al., 2007, Rochette et al., 2010).

Introduction of alien species, either natural (via dispersion) or human induced (during transplanting organisms for aquaculture or transport in ship ballasts), is now considered as a major threat for marine biodiversity (Bax et al., 2003). Indeed, introduction of non-native species may have biological effects on native species and a variety of cascading effects in the marine environment (Grosholz, 2002). Coastal and estuarine habitats are considered as the most heavily impacted by invasions on Earth (Grosholz, 2002; Paavola et al., 2005).

To maintain the ecological functions of essential fish habitat and to facilitate decision-making concerning their management it is thus fundamental to estimate the consequences of disturbance in these systems (Rubec et al., 1999; Beck et al., 2001) and especially to analyse how alien species disturb native populations.

The Mont Saint-Michel Bay (MSMB, France), located on the western part of the English Channel (Figure 1), is a vast and productive coastal area with a very high ecological value. Since 1979, this bay is listed in the World Heritage Sites (UNESCO) and its environment is protected by the International convention of Ramsar (1971) and by the European nature conservation network "NATURA 2000". The bay suffers from human pressure and especially from the introduction of an invasive species, the American slipper-limpet Crepidula fornicata (L., 1758). This small gastropod, native of the North American Atlantic coast (Walne, 1956), was unintentionally imported along with American oysters (Crassostrea virginica) in the 1970's (Blanchard, 1997). Slipper-limpets can have a wide range of distribution but individuals prefer soft bottoms and particularly muddy areas (Barnes et al., 1973, Montaudouin and Sauriau, 1999). Soft bottom areas are also the most appropriate for many fishes species, and especially flatfishes (Gibson, 1994). In coastal areas of the Bay of Biscay (France), Le Pape et al. (2004) showed that slipper-limpet decreased juvenile common sole abundance inside the nursery grounds, even if no incidence on the nursery extent was demonstrated. As habitat structure governs the distribution of demersal and benthic species because of their influence on the amount of preys and shelters (Katsanevakis et al., 2009; Nordström and Booth, 2007; Shucksmith et al., 2006; Stoner and Titgen, 2003), the question is here to analyse if slipper-limpet, by modifying benthic communities, trophic dynamics and habitat structure, influence flatfishes distribution in the MSMB. The link between the distributions of four flatfish species (common sole Solea solea, L.; plaice Pleuronectes platessa, L.; brill Scophthalmus rhombus, L. and flounder Platichthys flesus, L.) and the spread of slipper-limpet was thus analysed in the MSMB. The main goal was to map flatfish distribution in MSMB at the end of the 1970's and thirty years later in order to compare their distributions with slipper-limpets extent for the three last decades. 


\section{Material and methods}

\subsection{Study site}

The MSMB is located in North-West France, in the western part of the English Channel (latitude $48^{\circ} 40^{\prime} \mathrm{N}$, longitude $1^{\circ} 35^{\prime} \mathrm{W}$; Figure 1). This bay is a semi-diurnal system with a high tidal range, reaching $14 \mathrm{~m}$ during the highest spring tides (Larsonneur, 1994). About half of this wide and shallow bay $\left(500 \mathrm{~km}^{2}\right.$, depth $\left.<20 \mathrm{~m}\right)$ consists of mudflats $\left(210 \mathrm{~km}^{2}\right)$ and intertidal salt marshes $\left(40 \mathrm{~km}^{2}\right)$, which make the MSMB the most important salt-marsh area in Europe (Lefeuvre et al., 2000).

This bay is one of the most important nurseries in the English Channel for several fish species of commercial interest such as sea bass Dicentrarchus labrax, whiting Merlangius merlangius, flatfishes (common sole and plaice) and elasmobranchs (Raja spp) (Legendre, 1984; Lafaille et al., 1998). The MSMB also represents an important site for migration and wintering of many birds and waterbirds (Le Drean-Quenec'h Du et al., 1995).

This high productive area provides important ecological services and many activities such as tourism, fishing and shellfish farming are carried out in the bay (Le Mao et al., 2004). Since the late seventies, the bay hosts the invasive slipper-limpet (Blanchard, 1995) with a biomass reaching $150000 \mathrm{t}$ at the beginning of the XXI century (Blanchard, 2006). This species is the most represented among the filter feeders within the bay (Loomis and VanNieuwenhuyze, 1985; Blanchard, 1997; Blanchard and Ehrhold, 1999; Arbach Leloup et al., 2008).

\subsection{Sampling methods}

\subsubsection{American slipper-limpet}

At the end of the 1970's, Aubin (1979) conducted a survey on slipper-limpets in the western part of MSMB. The benthic fauna was sampled with a Smith Mac-Intyre grab $\left(0.1 \mathrm{~m}^{2}\right)$ in December 1978, January and February 1979. As scientists knew that slipper-limpets were only present in this part of the bay, the sampling scheme focused on a restricted area (Figure 2a). All grab samples (36 samples) were sieved on a $1 \mathrm{~mm}$ mesh and organisms were preserved in formaldehyde $10 \%$. Back to the laboratory, species were identified. At each station, slipper-limpets were counted and data were expressed in densities (ind. $\mathrm{m}^{-2}$ ).

A new slipper-limpet population survey was undertaken in May 2003 and 2004 in MSMB (Blanchard, 2009). This study was carried out on stations using sonar and video observations associated with benthic samples (Figure $2 b$ ). Sonar first allowed the exclusion of areas without limpets. Then, in the limpet area, three samples $\left(0.25 \mathrm{~m}^{2}\right.$ each) were taken at each station (65 stations) using a Hamon grab or by diving. The samples were sieved on a $2 \mathrm{~mm}$ mesh and animals were frozen. Back to the laboratory, the limpets were brushed to remove epibionts, cleaned, drained and weighed. The biomass for a station corresponded to the mean value of the three samples expressed in $\mathrm{g} \mathrm{m}^{-2}$ (total fresh weight).

To compare data from 1978-1979 with those from 2003-2004, densities from the first survey were transformed in biomass, using a mean weight per individual of $5.18 \mathrm{~g}$ (calculated from Blanchard, 2005). 


\subsubsection{Flatfish}

Trawl surveys were realized in October, in 1979 and in 1980. Hauls were performed with a $12 \mathrm{~m}$ wide and $10 \mathrm{~m}$ high opening otter trawl using a $24 \mathrm{~mm}$ stretched mesh net cod end. A total of 43 trawls hauls in 1979 and 15 in 1980 were conducted at 3 knots during 30 min and 20 min respectively (Figure 3a), covering approximately $29000 \mathrm{~m}^{2}$ in.

Another survey was performed in August 2008. Flatfish were caught with a $2.9 \mathrm{~m}$ wide and $0.5 \mathrm{~m}$ high opening beam trawl using a $20 \mathrm{~mm}$ stretched mesh net cod end. Forty-two beamtrawl hauls were carried out (Figure $3 b$ ) at 2.5 knots for 15 min, each covering approximately $3400 \mathrm{~m}^{2}$.

During all surveys, all flatfish were identified, measured and counted. Then, catch densities were expressed as number of individuals per $10000 \mathrm{~m}^{2}$.

\subsection{Data analysis}

\subsubsection{Preliminary analyses and validation of data}

\subsubsection{Slipper-limpet}

In 2003, the sampling survey was performed in the south and in the east of the BMSM while in 2004, stations were located in the western part of the bay. Data were compiled in one database to map a unique recent repartition of slipper-limpet within the entire BMSM. We assumed that there are little variations in limpet distribution between the two years, considering its lack of mobility (Blanchard, 1997).

\subsubsection{Flatfish}

Dab (Limanda limanda) and turbot (Psetta maxima) were very scarce in flatfishes sampling (less than 5 individuals), which lead to study only 4 of the 6 fished flatfish species: common sole, plaice, flounder and brill. Regarding these species, majority of common sole, plaice, and brill were juveniles (Table 1). On the contrary, both juvenile and mature flounders were caught in 1979-1980.

Sampling schemes (stations sampled) were different in 1979 and 1980 but the patterns of flatfish distribution were equivalent, which allowed pooling these data.

To make sure that a comparison between August 2008 and October 1979-1980 was possible, ie to avoid any seasonal biases, data from another survey performed in August 1978 and focused on common sole and plaice only were compared with observations made in October 1979-1980. For these two species, no seasonal variations were observed between August and October suggesting the same conclusions for all the flatfish species of this Bay.

Use of different sampling gears in 1979-1980 (large otter trawl) and 2008 (small beam trawl) could have biased a comparison between densities, even if these two gears did not seem to have significantly different efficiency for juvenile sole (Dorel et al., 1991). For this reason the present study mainly focused on the analysis of changes in the distribution of flatfishes, from the following mapping approach. 


\subsubsection{Mapping}

Spatial boundaries of the mapping area were chosen as a compromise between the amount of sampling stations and their distribution in the different flatfish trawl surveys (Fig. 3ab); few external stations, specific of each survey and located outside the area studied during the two periods, were removed from the dataset.

Comparison between current and historical distributions of species required interpolated densities within the studied area. Interpolation was performed using ordinary kriging (Kitanidis 1997; Christakos 2000). This geostatistical technique examines spatial structure in the dataset to determine interpolation parameters. This structure is established with the construction of semivariograms (Matheron, 1971) fitted to a theoretical model (e.g. linear, spherical, gaussian or exponential). Modelling was performed with R software (library "gstat").

To minimize skewing of distributions, raw data were transformed using $Z=\log (x+1)$. As patchiness of flatfishes was assumed to be constant over time, spatial structure of recent (2008) and historical (1979-1980) data were combined to fit a common variogram, however different for each species. Best fits were found using the exponential theoretical model. To map interpolated densities of each species for recent and historical periods, models were applied to a regular grid of points covering the study area. Considering the spatial distribution and the variability in densities of samples, interpolations were made with a minimum of 3 stations until a distance of $2 \mathrm{~km}$ for slipper-limpet and $5 \mathrm{~km}$ for flatfish. Despite these constraints, interpolations covered $96 \%$ and $100 \%$ of the study area for flatfishes in 19791980 and 2008 respectively.

To distinguish gradients of densities, predictions of the regular grid for each map were ranged in classes. The first class contained all stations of the grid where the species is not present. Other interpolated densities (i.e. positive) of the regular grid were classed in 3 quantiles, each containing $33 \%$ of the remaining stations. Resulting maps of predicted densities were thus represented with a 4-levels (absence, low, medium and high densities) grey scale whose limits were different from a species to another and between periods. These maps thus represented relative densities and avoid bias related to different trawl efficiency. Changes in slipper-limpet extent and flatfish distribution in the three last decades were analysed from these maps. In addition, proportions of null densities (absence) were calculated and differences between the two periods were statistically compared. Western limit of the distribution was reported for each period and distance between the two limits was also calculated.

Finally the relation between limpet biomass and flatfish densities was analysed on the recent period. Raw survey data were 0-inflated and were not appropriate for graphical analysis nor for parametric test (Le Pape et al., 2003). Thus, for each flatfish species, the proportion of interpolated density in the different quartile was compared for the different levels of limpet biomass and tested with a $\mathrm{X}^{2}$ test.

\section{Results}

In 1978-1979, American slipper-limpets were only located in two stations with very low densities: 5 and 24 ind. $\mathrm{m}^{-2}$, which correspond to an approximate biomass of 26 and $124 \mathrm{~g} \mathrm{~m}^{-}$ 2 respectively (Figure 2a). Experts' knowledge assures that in 1978-1979, this mollusc was not present elsewhere in the bay (Blanchard, 1995). In 2003-2004, slipper-limpets distribution was dramatically larger: they were not only located in the western part of the bay, 
but spread also towards the centre and the north-east. Maximum biomass reached more than $11500 \mathrm{~g} \mathrm{~m}^{-2}$ and slipper-limpets cover approximately half of the bay (Figure 2b).

Changes in flatfish distribution between the two periods have also been noticed. Common soles were widely distributed in the entire bay at the end of 70's with a peak distribution in the eastern part (Figure 3a). In 2008, common soles were absent from the western part but maximum densities were located in the same place, in the east (Figure 3b). Plaice spread in almost the entire bay in 1979-1980 and maximum densities were reached in the northeast (Figure 3c). In 2008, plaices were totally absent from the west and highest densities were found in the east (Figure 3d). Flounders were only present in few stations in 1979-1980, in the southwest and in the east (Figure 3e); they were totally absent from the western part of the bay in 2008 (Figure 3f). The brill situation was extreme: while it was present in the entire bay in 1979-1980 (Figure 3g), it is yet only found in the east (Figure 3h). Thus, flatfish spatial range has changed and reduced while the slipper-limpet was extending its distribution.

Western limit in common sole distribution has moved eastward from $5.6 \mathrm{~km}$ between 1979 1980 and 2008. This limit has also moved eastward from $8.9 \mathrm{~km}, 10.0 \mathrm{~km}$ and $14.5 \mathrm{~km}$ for plaice, flounder and brill respectively. This shift in the flatfish distribution western limit is also shown by the highly significant $\left(X^{2}\right.$ test $p$-value $\left.<10^{-12}\right)$ increase in zero in flatfish densities (Figure 3).

When analysing co-occurrence between slipper-limpet and flatfish during the recent period, for the four studied species found in the MSMB, densities are lower when the slipper-limpet biomass increase (Figure 4). These gradients in densities are significantly different for all flatfish ( $\mathrm{X}^{2}$ test, $\mathrm{p}$ value $<10^{-12}$ in all cases).

\section{Discussion}

\subsection{Slipper-limpet distribution}

The American slipper-limpet, a small gastropod native of the North American Atlantic coast, invaded massively the Western Europe coastal area since the beginning of the $20^{\text {th }}$ century (Minchin et al., 1995). The first observation of this gastropod in the MSMB was reported in 1976 (Retière, 1979) in the western part of the bay, in the Corbière bank in front of Cancale (Figure 2a). Slipper-limpet propagation in the bay began in the western sector to reach the centre and east of the bay in 2003-2004 (Figure 2b). A recent study comparing data from 1996 and 2003-2004 showed that during this period, the slipper-limpet population grew by 50 $\%$. As a consequence, in 2003-2004, $25 \%$ of the bay was covered by slipper-limpets at their highest density levels (Blanchard, 2009). Blanchard (2009) considered that the MSMB has not reached its saturation level, suggesting that slipper-limpet propagation in the MSMB is not complete and may progress eastward. Different explanations for this extension are expressed (Blanchard, 2009). Slipper-limpets benefit from several biological advantages and from favourable environmental conditions in the bay: water circulation and weak currents in the bay of Cancale favour larvae settlement whereas high productivity prevents it from food limitation. Temperature in the MSMB is within the optimal range for slipper-limpet and in the context of climate change and increasing temperature, the dispersion of $C$. fornicata, only sensitive to cold winters (Thieltges et al., 2004), would be stimulated. Human activities are also involved since oyster farming enhance slipper-limpet development, and shellfish dredging / fish trawling facilitate slipper-limpet spread (Blanchard, 2009). Moreover natural predation rate is low in Europe (Blanchard, 1997). Experimental tests performed in the northern Wadden Sea showed that the slipper-limpet natural predators, the crab Carcinus maenas and the sea star Asteria rubens, preferred blue mussels to slipper-limpets (Thieltges et al., 2004). Predation by waterbirds has not been studied in the BMSM but appeared limited elsewhere in Europe (Thieltges et al., 2004). 


\subsection{Flatfish spatial distribution}

\subsubsection{Current state and evolution}

In the present study, a direct comparison of flatfish densities between the two periods was not quantitatively possible: fishing gears and their related efficiency changed from a period to another and interannual recruitment variability could not be taken into account from a single year survey (2008). This induced the present semi-quantitative approach using relative distribution of flatfish densities. Almost all flatfishes distributions have changed between the late 1970's and the late 2000's: flatfishes have left the western part of the bay and their spatial ranges have significantly decreased (Figure 3).

\subsubsection{Cause}

Habitat suitability for flatfish, a mix between abiotic and biotic factors, is especially governed by food availability, predation pressure and temperature (Gibson, 1994). Slipper-limpets can disturb flatfish at different levels. Slipper-limpet shells accumulation deeply modifies the habitat structure and these modifications have different consequences. The first consequence of the substratum nature modification is preventing bentho-demersal species to bury in the sediment. The substratum preferences of the four flatfish species in this study are soft bottoms, sand or mixed sand and mud (Gibson, 1994; Elliott and Dewailly, 1995). On the contrary slipper-limpet shell mats are not a suitable habitat for bentho-demersal species. By covering the substrate and modifying its nature, slipper-limpets prevent juvenile and adult flatfish to settle and to bury, which may indirectly increase their vulnerability to predation (Gibson, 1994). On the other hand, limpets, by changing benthic fauna and catching a large part of the primary production, change the trophic structure (Arbach-Leloup et al., 2008), which can affect food availability for flatfish.

\subsubsection{Slipper-limpet consequences on nursery size}

The MSMB is an important nursery ground for flatfishes: during the sampling surveys, the major part of flatfish catches concerned immature fish (Table 1). As predation strongly influences juvenile mortality (van der Veer and Bergman, 1987; Johnson, 2007; Juanes, 2007), flatfish juveniles that settle in an inappropriate substrate (i.e. cover with shells) cannot bury, are vulnerable for their predators and have low chance to survive. High biomasses of slipper-limpet were already known to strongly reduce densities of juvenile sole (Le Pape et al., 2004). The present study reinforces this previous knowledge and demonstrates that juvenile flatfish distribution is reduced in the MSMB. Flatfish distributions are significantly reduced while co-occurrence is observed with slipper-limpet and quite no flatfish are found at the highest density of slipper-limpet (Figure 4). As demonstrated from xenobiotics exposure (Moles et al., 1994) or stable isotopes footprints (Kostecki et al., 2010), juvenile flatfish migrations are very limited and they can not move far from unfavourable settlement area. Thus, the settlement suitable area and the related nursery size are reduced in response to limpet extent.

\subsubsection{Slipper-limpet consequences on residual flatfish habitat}

By changing the habitat structure, limpets compelled flatfish adults to move eastward in the bay. This induces a shift in flatfish distribution to suitable sediment which leads to a concentration of remaining flatfish in the eastern part of the BMSM. The presence of slipper shells, by reducing the suitable habitat size, should limit this avoiding strategy on residual suitable slipper-limpet free habitat. 
In the remaining habitat, food limitation could result from slipper-limpet invasion. Primary production would be higher in the BMSM without the slipper-limpet filtering activity (Cugier et al., 2010). This primary production is consumed by the slipper-limpet and is not yet available for the other suspension feeder benthic invertebrates, which are also common preys for flatfishes (Arbach Leloup et al., 2008; Elliott and Dewailly, 1995). Food availability and growth could decrease in the residual habitat in the MSMB because of density dependent competition in a smaller area.

\subsubsection{Possible long-term consequences on population size and renewal}

In flatfish population, post-settlement mortality, linked to nursery habitat capacity, affects recruitment strength and population size (Gibson, 1994; Johnson, 2007). Both the nursery ground area and suitable habitats for remaining juvenile and adult flatfish in MSMB is reduced due to changes in habitat structure linked to slipper-limpet extent. Thus, slipperlimpet can damage flatfish populations in the Western English Channel and have consequences on related fisheries. One can moreover imagine that other benthic species, like rays, could also be affected.

\section{Acknowledgments}

This study was supported by the French National Program on Coastal Environments (NOCES). We would like to thank P. Le Mao and the crew of the R/V Louis Fage for their help during sample collection. We are also very grateful to $Y$. Désaunay and $P$. Beillois who provided fish data from the end of the 1970's. The authors are also grateful to the two anonymous reviewers for their helpful advices. 


\section{References}

Arbach Leloup, F., Desroy, N., Le Mao, P., Pauly, D., Le Pape, O., 2008. Interactions between a natural food web, shellfish farming and exotic species: The case of the Bay of Mont Saint-Michel (France). Estuarine, Coastal and Shelf Science 76, 111-120.

Aubin, D., 1979. Influence de l'envasement sur les activités conchylicoles de la baie de Cancale. Rapport Muséum National d'Histoire Naturelle. Laboratoire Maritime du Muséum National d'Histoire Naturelle, Dinard. 78 pp.

Barnes, R. S. K., Coughlan, J., Holmes, N. J., 1973. A preliminary survey of the macroscopic bottom fauna of the Solent, with particular reference to Crepidula fornicata and Ostrea edulis. Proceedings of the Malacological Society of London 40, 253-2575.

Bax, N., Williamson, A., Aguero, M., Gonzales, E., Geeves,W., 2003. Marine invasive alien species: a threat to global diversity. Marine Policy 27, 313-323.

Beck, M. W., Heck, K. L., Able, K. W., Childers, D. L., Eggleston, D. B., Gillanders, B. M., Halpern, B., Hays, C. G., Hostino, K., Minello,T. J., Orth, R. J., Sheridan, P., Weinstein, M. P., 2001. The identification, conservation and management of estuarine and marine nurseries for fish and invertebrates. Bioscience 51, 633-641.

Blanchard, M., 1995. Origine et état de la population de Crepidula fornicata (Gastropoda Prosobranchia) sur le littoral français. Haliotis 24, 75-86.

Blanchard, M., 1997. Spread of the slipper-limpet (Crepidula fornicata) in Europe. Current state and consequences. Scientia marina 61 (sup2), 109-118.

Blanchard, M., 2005. Dynamique de la population de crépidule (Crepidula fornicata) en Baie du Mont Saint-Michel. Rapport Ifremer Brest, 33 pp.

Blanchard, M., 2006. Cartographie et évaluation du stock de crépidules en baie du Mont Saint-Michel, en 2004. Rapport Ifremer Brest, 34 pp.

Blanchard, M., 2009. Recent expansion of the slipper-limpet population (Crepidula fornicata) in the Bay of Mont-Saint-Michel (Western Channel, France). Aquatic Living Resources 22, 11-19.

Blanchard, M. and Ehrhold, A., 1999. Cartographie et évaluation du stock de crépidules (Crepidula fornicata L.) en baie du Mont Saint-Michel. Haliotis 28, 11-20.

Christakos, G., 2000. Modern spatio-temporal geostatistics. Oxford University Press, New York. 288 pp.

Costanza, R., Darge, R., Degroot, R., Farber, S., Grasso, M., Hannon, B., Limburg, K., Naeem, S., Oneill, R.V., Paruelo, J., Raskin, R.G., Sutton, P., Vandenbelt, V., 1997. The value of the world's ecosystem services and natural capital. Nature 387, 253-260.

Cugier, P., Struski, C., Blanchard, M., Mazurié, J., Pouvreau, S., Olivier, F., Trigui, J.R., Thiébaut, E., 2010. Assessing the role of benthic filter-feeders on phytoplanktonic production: the case of the Mont Saint-Michel Bay, France. Journal of Marine Systems 82, 21-34.

Dorel, D., Koutsikopoulos, C., Desaunay, Y., Marchand, J., 1991. Seasonal distribution of young sole (Solea solea (L.)) in the nursery ground of the Bay of Vilaine (Northern Bay of Biscay). Netherlands Journal of Sea Research 27, 297-306. 
Elliott, M and Dewailly, F., 1995. The structure and components of European estuarine fish assemblages. Netherlands Journal of Aquatic Ecology 29(3-4), 397-417.

Gibson, R. N., 1994. Impact of habitat quality and quantity on the recruitment of juvenile flatfishes. Netherlands Journal of Sea Research 32, 191-206.

Grosholz, E., 2002. Ecological and evolutionary consequences of coastal invasions. Trends in Ecology and Evolution 17, 22-27.

Johnson, DW., 2007. Habitat complexity modifies post-settlement mortality and recruitment dynamics of marine fish. Ecology 88, 1716-1725.

Johnson, L.L., Landahl, J.T., Kubin, L.A., Horness, B.H., Myers, M.S., Collier, T.K., Stein, J.E., 1998. Assessing the effects of anthropogenic stressors on Puget Sound flatfish populations. Journal of Sea Research 39, 125-137.

Juanes, F., 2007. Role of habitat in mediating mortality during the post-settlement transition phase of temperate marine fishes. Journal of Fish Biology 70, 661-677.

Katsanevakis, S., Maravelias, C.D., Damalas, D., Karageorgis, A.P., Tsitsika, E.V., Anagnostou, C., Papaconstantinou, C., 2009. Spatio-temporal distribution and habitat use of commercial demersal species in the eastern Mediterranean Sea. Fisheries Oceanography $18,439-457$.

Kitanidis, P., 1997. Introduction to geostatistics: Application to hydrology. Cambridge University Press, Cambridge, 249 pp.

Kostecki, C., Le Loc'h, F., Roussel, J.M., Desroy, N., Huteau, D., Le Bris, H., Le Pape, O. 2010. Dynamics of an estuarine nursery ground: the spatio-temporal relationship between the river flow and the food web of the juvenile common sole (Solea solea) as revealed by stable isotopes analysis. Journal of Sea Research 64, 54-60.

Laffaille, P., Brosse, S., Feunteun, E., Baisez , A., Lefeuvre, J.C., 1998. Role of fish communities in particulate organic matter fluxes between salt marshes and coastal marine waters in the Mont Saint-Michel Bay. Hydrobiologia 373-374, 121-133.

Larsonneur, C., 1994. The Bay of Mont-Saint-Michel: a sedimentation model in a temperate macrotidal environment. Senckenbergiana Maritima 24, 3-63.

Le Drean-Quenec'h Du, S., Maheo, R., Boret, P., 1995. Mont Saint-Michel bay: a site of international importance for wintering and migrating paleoarctic waders. Wader Study Group Bull. 77, 50-54.

Le Mao, P., Retière, C., Le Bec, C., Gerla, D., 2004. Gérer un anthroposystème littoral à forte valeur patrimoniale : comment relever ce défi en baie du Mont Saint-Michel? Oceanis 30(1), 95-115.

Le Pape, O., Chauvet, F., Mahevas, S., Lazure, P., Guerault, D., Desaunay, Y., 2003. Quantitative description of habitat suitability for the juvenile common sole (Solea solea, L.) in the Bay of Biscay (France) and the contribution of different habitats to the adult population. Journal of Sea Research 50, 139-149.

Le Pape, O., Guerault, D., Desaunay, Y., 2004. Effect of an invasive mollusc, American slipper-limpet Crepidula fornicata, on habitat suitability for juvenile common sole Solea solea in the Bay of Biscay. Marine Ecology Progress Series 277, 107-115. 
Le Pape, O., Baulier, L., Cloarec, A., Martin, J., Le Loc'h, F., Desaunay, Y., 2007. Habitat suitability for juvenile common sole (Solea solea, L.) in the Bay of Biscay (France): A quantitative description using indicators based on epibenthic fauna. Journal of Sea Research $57,126-136$.

Lefeuvre, J.C., Bouchard, V., Feunteun, E., Grare, S., Laffaille, P., Radureau, A., 2000. European saltmarsh diversity and functioning: the case of the Mont Saint-Michel bay, France. Wetland Ecology and Management 8, 147-161.

Legendre, C., 1984. La pêche artisanale sur le domaine intertidal de la Baie du Mont SaintMichel. Report CEE/University of Rennes 1, France, 222 pp.

Loomis, S. H. and VanNieuwenhuyze, W., 1985. Sediment correlates to density of Crepidula fornicata Linnaeus in the Pataguanset river, Connecticut. The Veliger 27, 266-272.

Matheron, G., 1971. The theory of regionalized variables and its applications. Cahiers du centre de Morphologie Mathématique 5, 212 pp.

Minchin, D., McGrath, D., Duggan, C. B., 1995. The slipper-limpet, Crepidula fornicata (L.), in Irish waters, with a review of its occurrence in the North eastern Atlantic. Journal of Conchology 35, 249-256.

Moles, A., Rice, S., and Norcross, B. L., 1994. Non-avoidance of hydrocarbon laden sediments by juvenile flatfishes. Netherlands Journal of Sea Research 32, 361-367.

Montaudouin, X. de- and Sauriau, P. G., 1999. The proliferating Gastropoda Crepidula fornicata may stimulate macrozoobenthic diversity. Journal of the Marine Biological Association, United Kingdom 79, 1069-1077.

Nordström, M. and Booth, D. M., 2007. Drift algae reduce foraging efficiency of juvenile flatfish. Journal of Sea Research 58, 335-341.

Paavola, M., Olenin, S., Leppakoski, E., 2005. Are invasive species most successful in habitats of low native species richness across European brackish water seas? Estuarine, Coastal and Shelf Science 64(4), 738-750.

Peterson, C. H., Summerson, H. C., Thomson, E., Lenihan, H. S., Grabowski, J., Manning, L., Micheli, F., Johnson, G., 2000. Synthesis of linkages between benthic and fish communities as key to protecting essential fish habitat. Bulletin of Marine Science 66, 759774.

Peterson, M., 2003. A conceptual view of environment-habitat-production linkages in tidal river estuaries. Reviews in Fisheries science 11(4), 291-313.

Retière, C., 1979. Contribution à la connaissance des peuplements benthiques du golfe normano-breton. Ph. D. Thesis. University of Rennes. 431 pp.

Rijnsdorp, A. D., Van Beek, F. A., Flatman, S., Millner, R. M., Riley, J. D., Giret, M., De Clerck, R., 1992. Recruitment of sole stocks, Solea solea (L.), in the northeast Atlantic. Netherlands Journal of Sea Research 29, 173-192.

Rochette, S., Rivot, E., Morin, J., Mackinson, S., Riou, P., Le Pape, O., 2010. Effect of nursery habitat degradation on flatfish population renewal. Application to Solea solea in the eastern Channel (Western Europe). Journal of sea Research 64, 34-44. 
Rubec, P.J., Bexley, J.C. W., Norris, H., Coyne, M.S., Monaco, M.E., Smith, S.G., Ault, J.S., 1999. Suitability modeling to delineate habitat essential to sustainable fisheries. American Fisheries Society Symposium 22, 108-133.

Shucksmith, R., Hinz, H., Bergmann, M., Kaiser, M.J., 2006. Evaluation of habitat use by adult plaice (Pleuronectes platessa, L.) using underwater video survey techniques. Journal of Sea Research 56, 317-328.

Stoner, A. W. and Titgen, R. H., 2003. Biological structures and bottom type influence habitat choices made by Alaska flatfishes. Journal of Experimental Marine Biology and Ecology 292, 43-59.

Thieltges, D.W., Strasser, M., Van Beusekom, J.E.E., Reise, K., 2004. Too cold to prosperwinter mortality prevents population increase of the introduced American slipper-limpet Crepidula fornicata in northern Europe. Journal of Experimental Marine Biology and Ecology 311, 375-391.

Van der Veer, H.W. and Bergman, M. J. N., 1987. Predation by crustaceans on a newly settled 0-group plaice Pleuronectes platessa population in the western Wadden Sea. Marine Ecology Progress Series 35, 203-215.

Van der Veer, H.W., Bergham, R., Miller, J.M., Rijnsdorp, A.D., 2000. Recruitment in flatfish, with special emphasis on North Atlantic species: Progress made by the Flatfish Symposia. Ices Journal of Marine Science 57, 202-215.

Walne, P. R., 1956. The biology and distribution of the slipper-limpet Crepidula fornicata in Essex rivers. Fishery Investigations 20, 1-50. 


\section{Figures}

Figure 1 : Map of the Mont Saint-Michel Bay with the location of the study area (light grey), the oyster $(\mathrm{O})$ and mussels $(\mathrm{M})$ cultures and the salt marshes. In the upper right corner of the figure: general location.

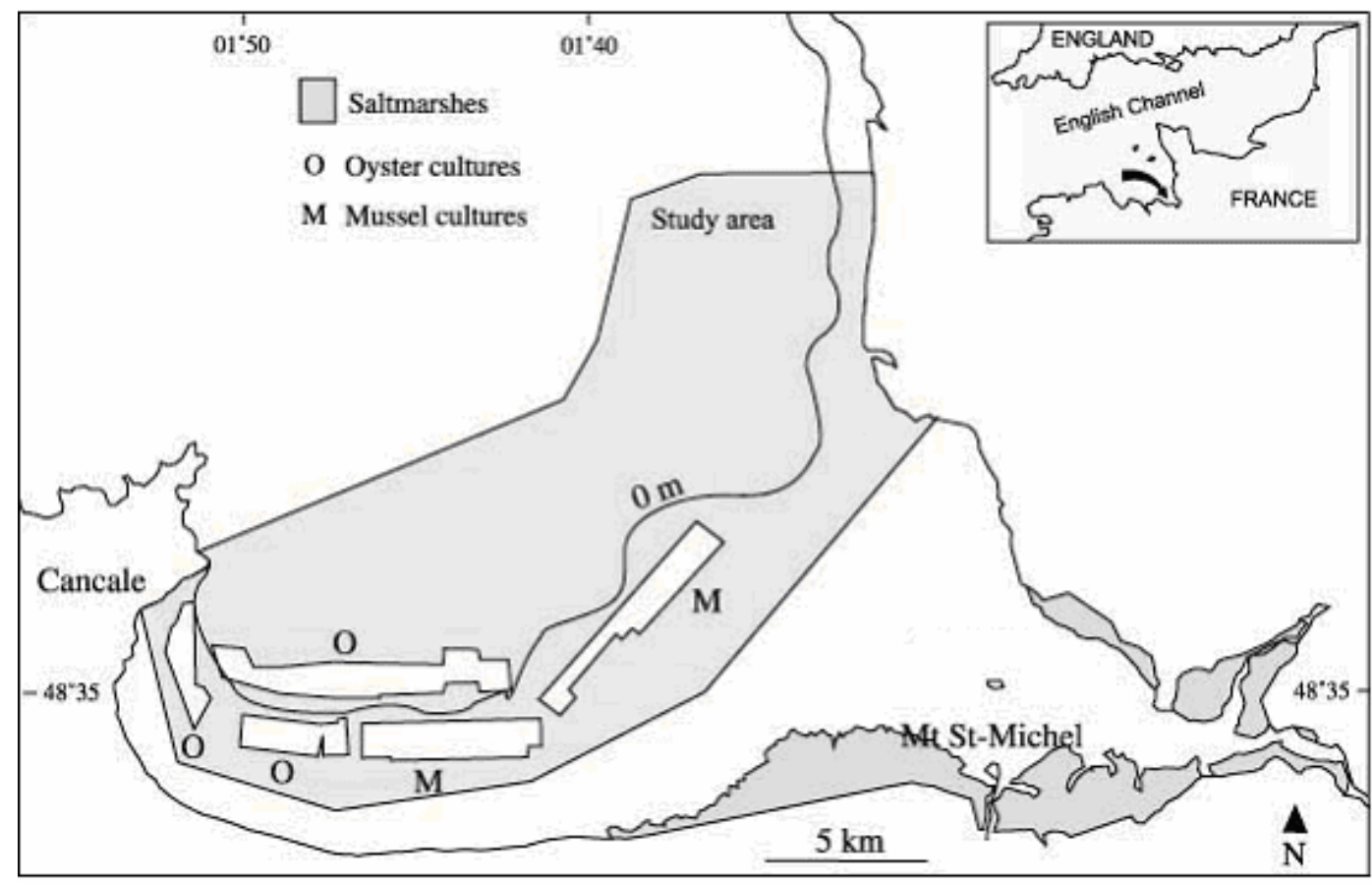


Figure 2 : American slipper-limpet distribution in 1978-1979 (a) and in 2003-2004 (b). Polygons inside the studied area represent oyster and mussels cultures of the respective studied period. No predictions were calculated within these cultures.

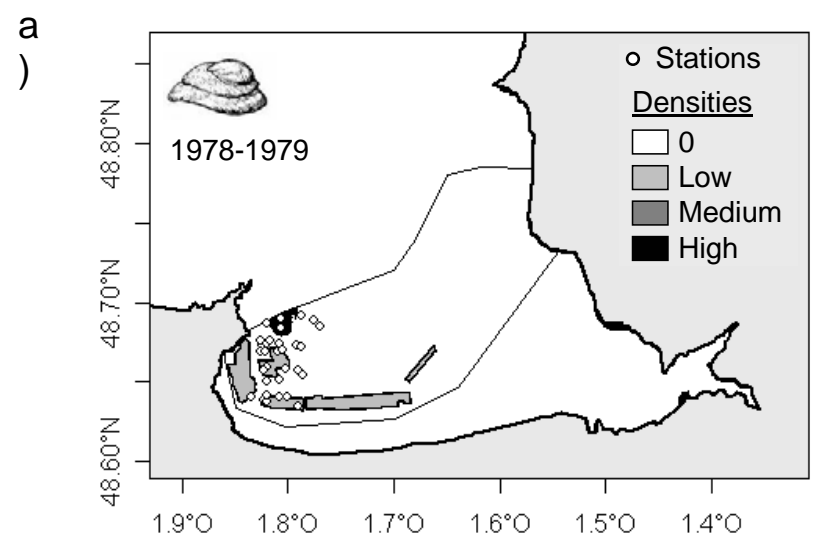

b)

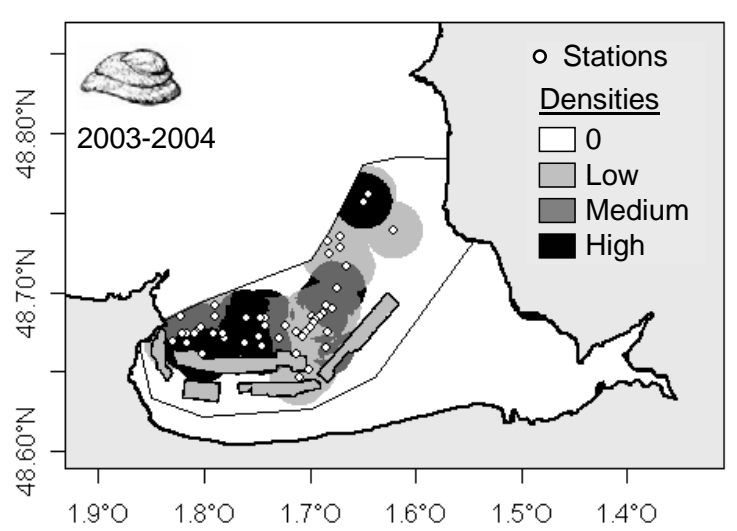


Figure 3 : Flatfish distribution in 1979-1980 and in 2008 for common sole Solea solea (a and b), plaice Pleuronectes platessa ( $c$ and $d$ ), flounder Platichthys flesus (e and $f$ ) and brill Scophthalmus rhombus ( $g$ and $h$ ). Polygons inside the studied area represent oyster and mussels cultures of the respective studied period. No predictions were calculated within these cultures. In the right lower corner is indicated the proportion of absence.

a)

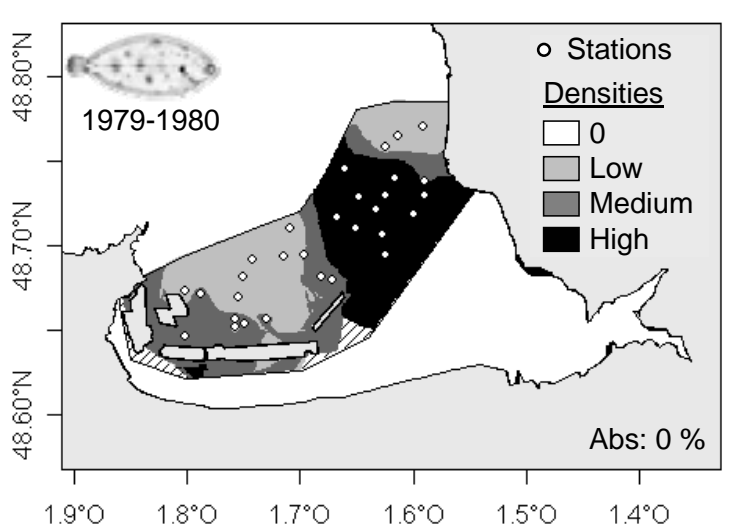

c)

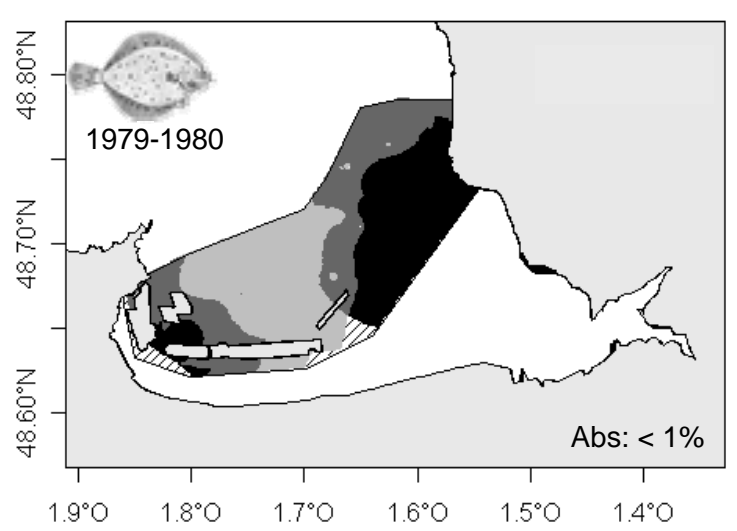

e)

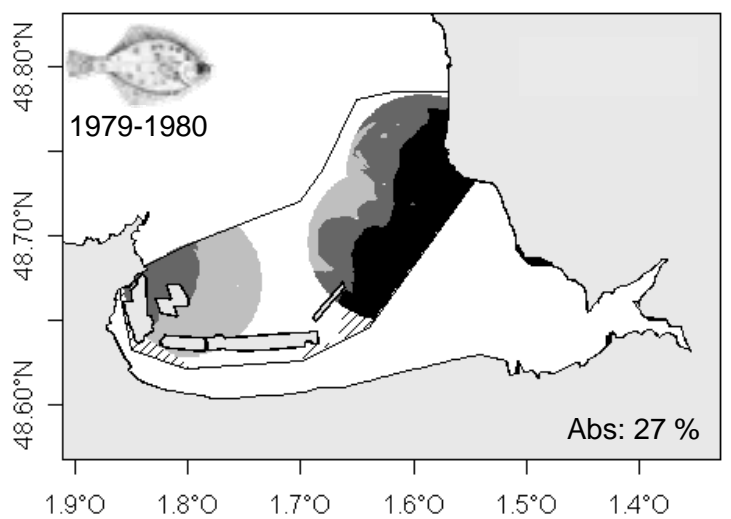

b)

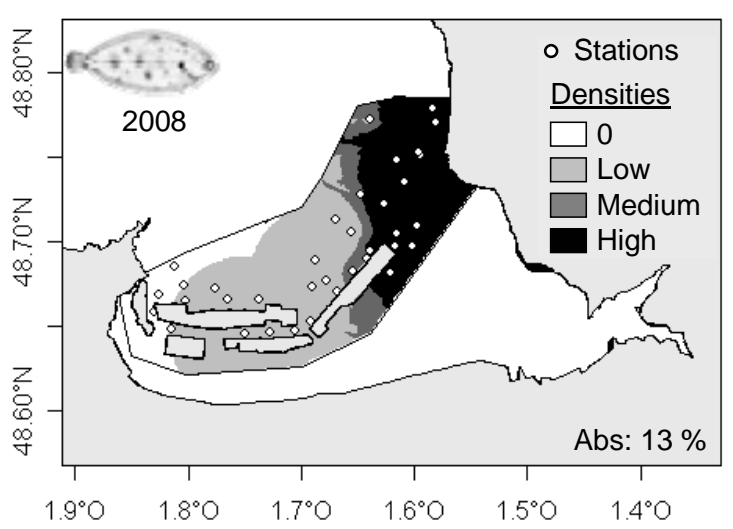

d)

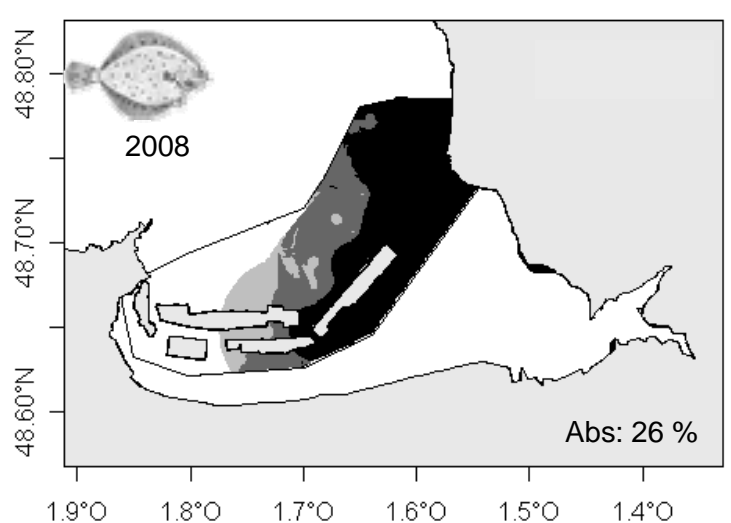

f)

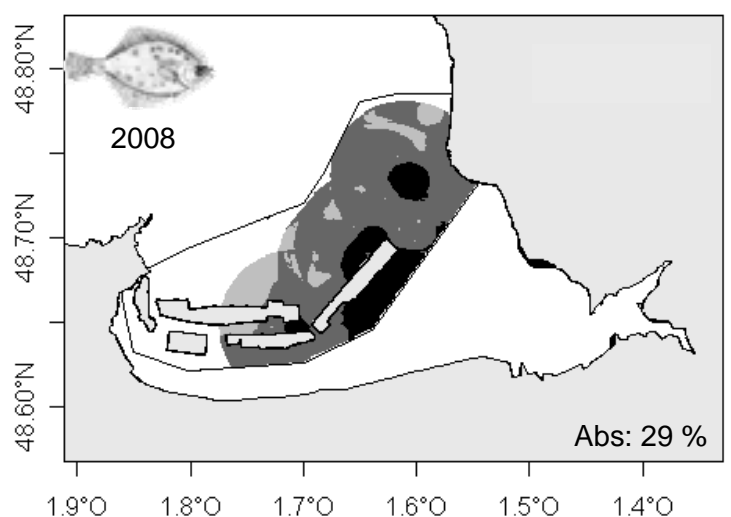


g)

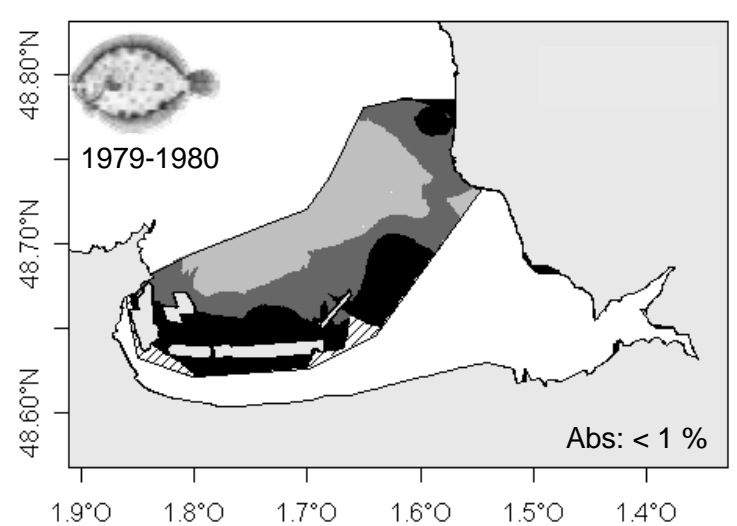

h)

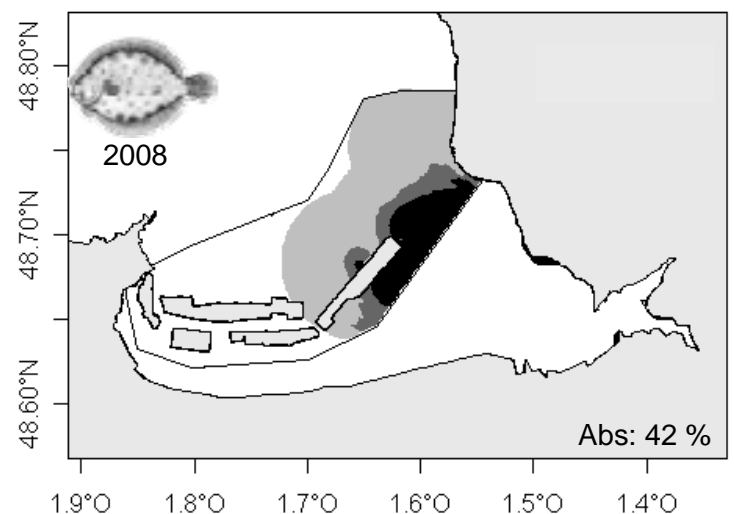


Figure 4 : Proportion of interpolated stations of the regular grid in each density class with relation to slipper-limpet biomass for common sole Solea solea (a), plaice Pleuronectes platessa (b), flounder Platichthys flesus (c) and brill Scophthalmus rhombus (d) for the recent period. The increasing grey gradient distinguishes classes of increasing densities of the flatfishes distributions: white for absence, light grey for low densities, dark grey for medium and black for high densities. Limits for the slipper-limpets biomass classes are: low ]0 ; 920], medium ]920; 2655] and high $>2655 \mathrm{~g} \mathrm{~m}^{-2}$.

a)

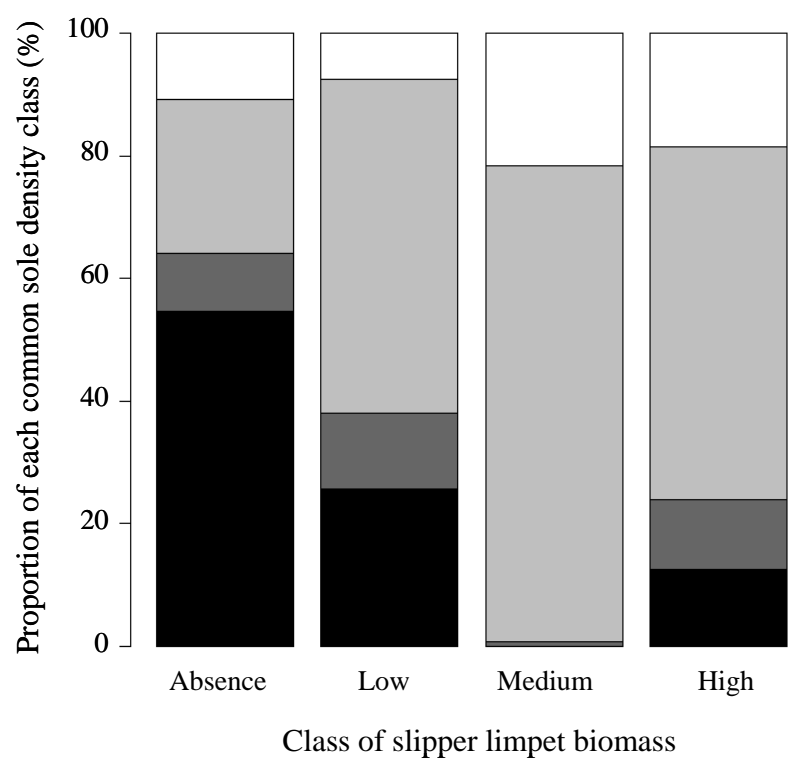

c)

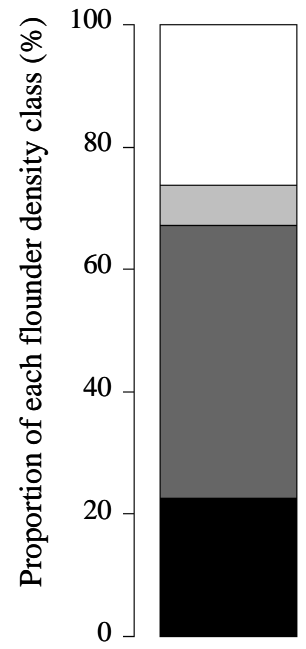

Absence

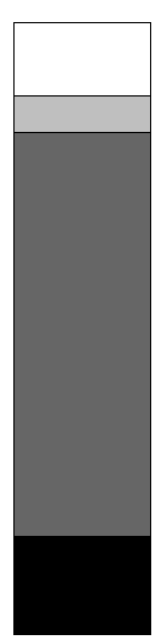

Low

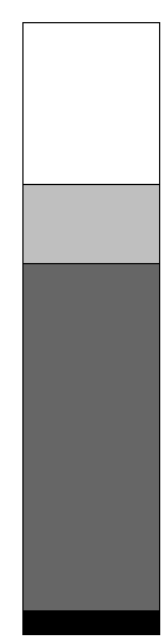

Medium

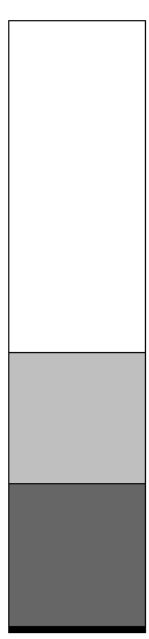

High

Class of slipper limpet biomass

b)

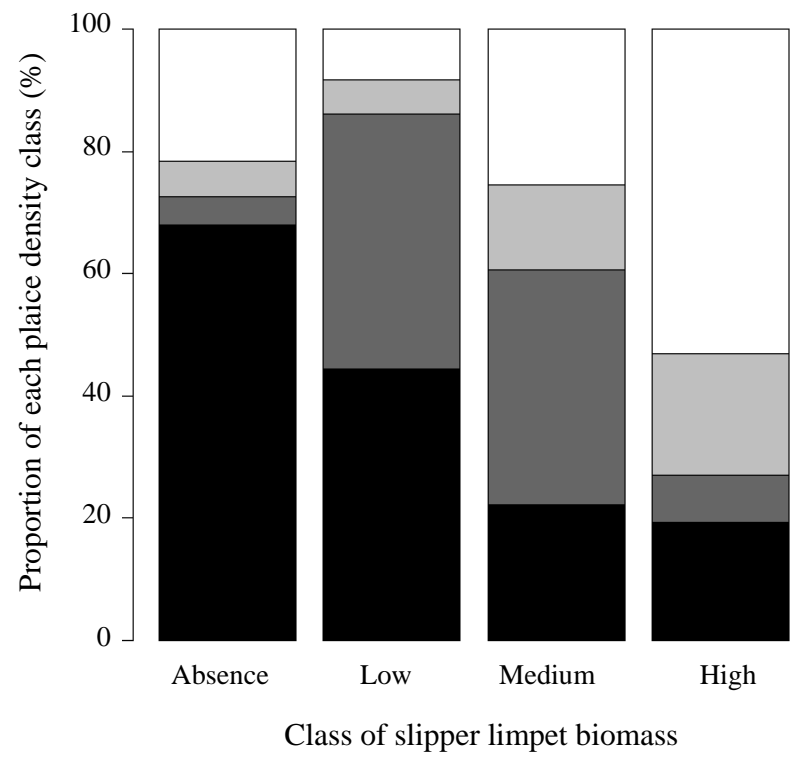

d)

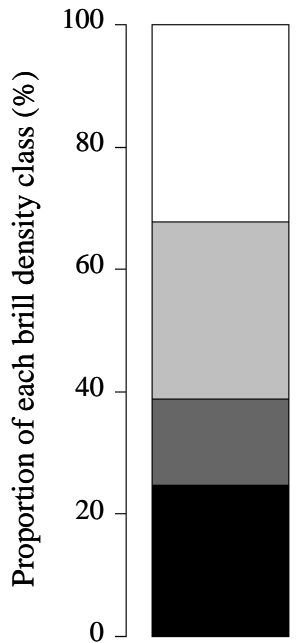

Absence

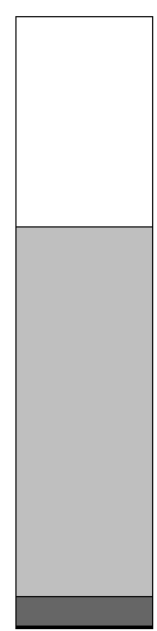

Low

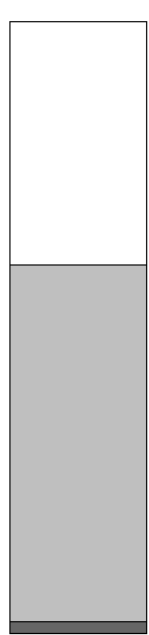

Medium

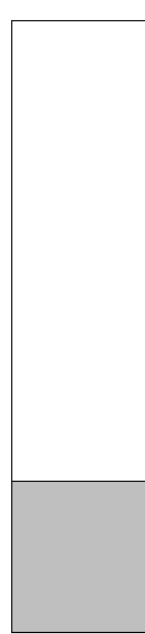

High
Class of slipper limpet biomass 


\section{Table}

Table 1 : Information on flatfish catches for each period

Total catches Juveniles (\%) and reference

\begin{tabular}{llll}
\hline 1979-1980 & Common sole & 5523 & $99 \%(<25 \mathrm{~cm}$; Dorel et al., 1991) \\
& Plaice & 936 & $96 \%(<30 \mathrm{~cm})$ \\
& Flounder & 383 & $37 \%(<25 \mathrm{~cm}$; Van der Land, 1991) \\
& Brill & 95 & $74 \%(<25 \mathrm{~cm}$; Quéro and Vayne, 1997) \\
\hline $\mathbf{2 0 0 8}$ & Common sole & 648 & $99 \%(<25 \mathrm{~cm}$; Dorel et al., 1991) \\
& Plaice & 199 & $99 \%(<30 \mathrm{~cm})$ \\
& Flounder & 12 & $83 \%(<25 \mathrm{~cm}$ Van der Land, 1991) \\
& Brill & 15 & $100 \%(<25 \mathrm{~cm}$ Quéro and Vayne, 1997$)$
\end{tabular}

